\title{
The Coapsys device to treat functional mitral regurgitation: In vivo long-term canine study
}

Masahiro Inoue, $\mathrm{MD}, \mathrm{PhD}^{\mathrm{a}}$

Patrick M. McCarthy, MDa,b

Zoran B. Popović, MD

Kazuyoshi Doi, MDa

Soren Schenk, MD

Hassan Nemeh, MD ${ }^{\mathrm{a}}$

Yoshio Ootaki, MD, $\mathrm{PhD}^{\mathrm{a}}$

Michael W. Kopcak, Jr, BA

Raymond Dessoffy, $A A^{\text {a }}$

James D. Thomas, MD ${ }^{c}$

Kiyotaka Fukamachi, MD, PhD

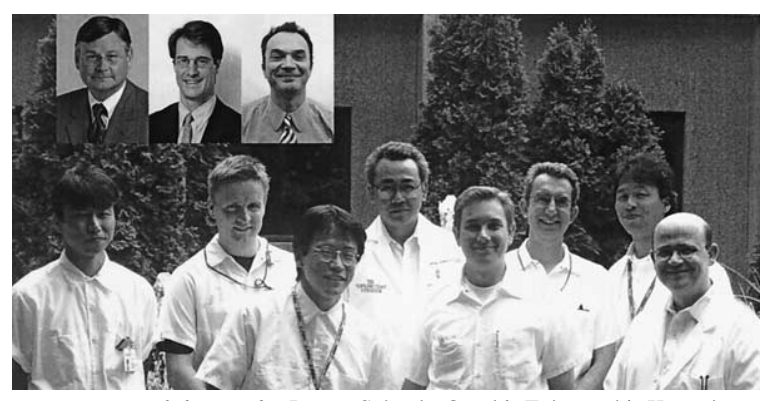

Front row, left to right, Inoue, Schenk, Ootaki, Fukamachi, Kopcak, Dessoffy, Doi, Nemeh. Back row, left to right, McCarthy, Thomas, Popović.
Objective: We evaluated the capability of the Myocor Coapsys device (Myocor, Inc, Maple Grove, Minn) to reduce functional mitral regurgitation in a canine model of dilated cardiomyopathy.

Methods: Functional mitral regurgitation with heart failure was induced in 7 dogs by rapid ventricular pacing. The Coapsys device, which consists of anterior and posterior epicardial pads connected by a subvalvular chord, was then implanted. Heart failure was maintained by continued pacing for 8 weeks. Hemodynamic and echocardiographic measurements were performed at pre- and postsizing and after 8 weeks. The Coapsys subvalvular chord was cut to verify that maintenance of valve competency was due to the device.
From the Department of Biomedical Engineering, ${ }^{a}$ Lerner Research Institute, Department of Thoracic and Cardiovascular Surgery, ${ }^{\mathrm{b}}$ Kaufman Center for Heart Failure, and Department of Cardiology, ${ }^{\mathrm{c}}$ The Cleveland Clinic Foundation, Cleveland, Ohio.

This study was financially supported by Myocor, Inc (Maple Grove, Minn). Patrick M. McCarthy, MD, is a consultant to Myocor, Inc (Maple Grove, Minn).

Read at the Eighty-third Annual Meeting of The American Association for Thoracic Surgery, Boston, Mass, May 4-7, 2003.

Received for publication May 1, 2003; revisions received Nov 19, 2003; accepted for publication Dec 1, 2003.

Address for reprints: Kiyotaka Fukamachi, $\mathrm{MD}, \mathrm{PhD}$, Department of Biomedical Engineering/ND20, The Cleveland Clinic Foundation, 9500 Euclid Ave, Cleveland, OH 44195 (E-mail: fukamach@ bme.ri.ccf.org).

J Thorac Cardiovasc Surg 2004;127:1068-77 $0022-5223 / \$ 30.00$

Copyright $\odot 2004$ by The American Association for Thoracic Surgery

doi:10.1016/j.jtcvs.2003.12.005
Results: All implants were performed off-pump without atriotomy. Mitral regurgitation was reduced in all animals; mean mitral regurgitation grade was reduced from $2.9 \pm 0.7$ to $0.7 \pm 0.8(P=.00005)$ and was maintained at $0.8 \pm 0.8$ after 8 weeks, without hemodynamic compromise or structural damage to the mitral valve. Mitral regurgitation returned to $3.6 \pm 0.8(P=.102$ versus presizing $)$ after cutting the Coapsys subvalvular chord.

Conclusion: The Coapsys device consistently and chronically reduced functional mitral regurgitation. This device is in clinical trials in the United States.

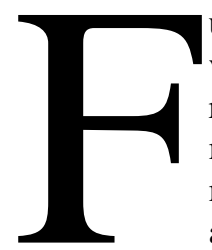

unctional mitral regurgitation (MR) occurs with a structurally normal valve as a complication of left ventricular (LV) dysfunction, and as a result, almost half the patients with LV dysfunction have at least moderate MR. ${ }^{1}$ Recently, studies revealed that changes in the 3-dimensional relationships between the LV and mitral apparatus (mitral annular dilatation and papillary muscle displacement) induce functional MR. ${ }^{2-8}$ Based upon this information, 3-dimensional restoration of mitral valve (MV) geometry is an appropriate means to treat patients with functional MR. A novel device, the Coapsys Annuloplasty System (Myocor, Inc, Maple Grove, Minn), was developed to treat functional MR. The Coapsys device is designed to correct valve dysfunction without requiring the use of cardiopulmonary bypass (CPB) or an open-heart access method. This study was conducted to evaluate the acute and chronic effects of the Coapsys device on MR in a canine model of functional MR. 

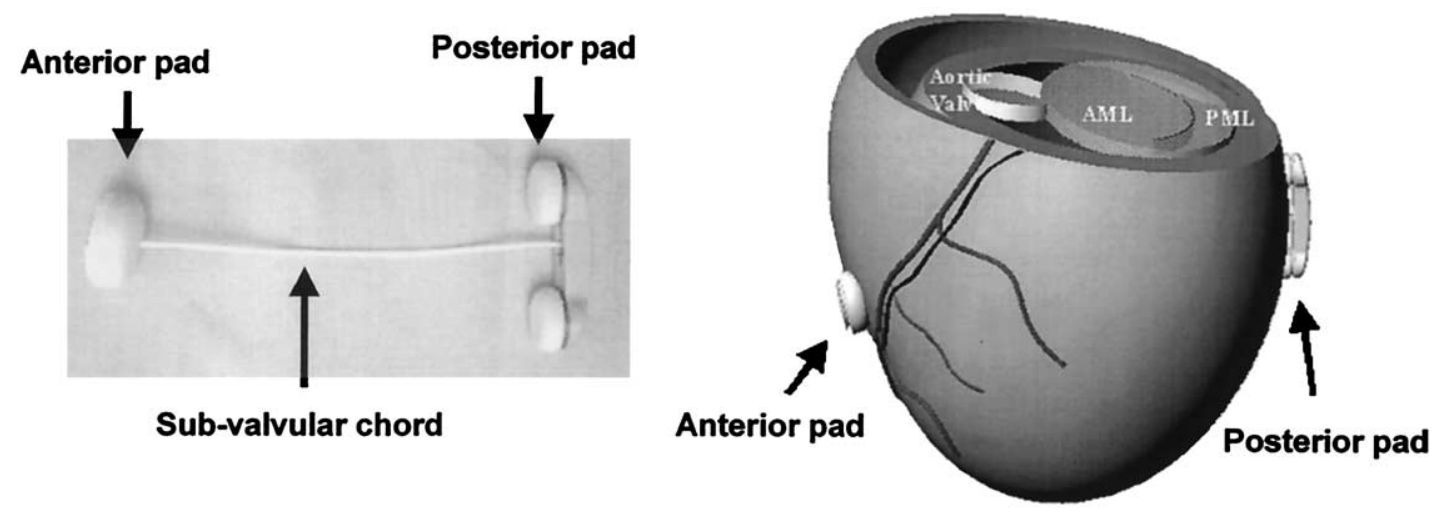

Figure 1. The Coapsys device consists of an epicardial anterior pad, an epicardial posterior pad, and a subvalvular chord (left). The 2 pads are located on the surface of the heart with the load-bearing subvalvular chord passing through the ventricle (right). AML, Anterior mitral leaflet; $P M L$, posterior mitral leaflet.

\section{Material and Methods \\ The Coapsys Concept and Coapsys Design}

The Coapsys concept and Coapsys device have been previously reported. ${ }^{9}$ Briefly, the Coapsys device was developed to treat patients with Carpentier type I (normal) or type IIIb (restrictive) valve leaflet motion. ${ }^{10}$ The Coapsys device consists of an epicardial posterior pad, epicardial anterior pad, and subvalvular chord. The 2 pads are located on the surface of the heart with the load-bearing subvalvular chord passing through the ventricle (Figure 1). The posterior pad has 2 heads, such that the annular head imparts shape change directly to the mitral annulus when the anterior and posterior pads are drawn together. The papillary head provides leverage at midpapillary muscle level to change the papillary muscle position (Figure 2). The device is tightened, under echocardiographic visualization on the beating heart, until MR is significantly reduced or eliminated. The polyester-covered anterior pad is adjustable, utilizing a deployable pin mechanism, and is fixed to the subvalvular chord after sizing the device during the procedure.

\section{In Vivo Study}

This study was approved by the Cleveland Clinic's Institutional Animal Care and Use Committee, and all animals received humane care in compliance with the "Guide for the Care and Use of Laboratory Animals" prepared by the Institute of Laboratory Animal Resources, National Research Council, and published by the National Academy Press, revised 1996.

\section{Animal Model}

Among several potential MR models, chronic rapid ventricular pacing was chosen in this study because the hemodynamic and echocardiographic changes are very similar to those found in human functional MR. ${ }^{11}$ Also, rapid ventricular pacing produces heart failure, ${ }^{4,11-13}$ which is a common comorbidity among this patient group.

The methodology of inducing and maintaining the model has been reported. ${ }^{12}$ Seven adult mongrel dogs (body weight $25.0 \pm$ $1.1 \mathrm{~kg}$ ) were paced via the right ventricular (RV) transvenous lead using rapid asynchronous ventricular pacing at 230 beats per minute for an average of $31 \pm 4$ days to induce functional MR with heart failure. No medication for heart failure, including diuretics, was given during the induction phase. At the end of the induction phase, the pacemaker rate was temporarily reduced to demand mode at 30 beats per minute so that the animal would resume normal sinus rhythm, and transthoracic 2-dimensional (2-D) echocardiograms were obtained to evaluate the progression of cardiac remodeling, the reduction of LV function, and development of MR and tricuspid regurgitation (TR; graded on a scale from $0+$ to $4+$ ). If MR was equal to or more than $2+$ at the presizing data point then plans were made for Coapsys implantation.

\section{Coapsys Implant Surgery}

On the date of study, the pacemaker was again reduced to demand mode, and the animal was anesthetized with thiopental $(15 \mathrm{mg} / \mathrm{kg})$ and intubated. The anesthesia was maintained with isoflurane $(0.5 \%-2.5 \%)$. The following hemodynamic and echocardiographic measurements were taken as the baseline closed-chest data point. A catheter with 2 Millar pressure sensors (Model SPC-562; Millar Instruments, Inc, Houston, Tex) was placed via the carotid artery to record aortic (AoP) and LV (LVP) pressures. A thermistor-tip balloon catheter (Criticath SP5507 TD catheter; Becton Dickinson Infusion Therapy System Inc, Sandy, Utah) was passed from the jugular vein to the pulmonary artery to monitor the pulmonary artery pressure and the central venous pressure. Cardiac output $\left(\mathrm{CO}_{\mathrm{SG}}\right)$ and stroke volume $\left(\mathrm{SV}_{\mathrm{SG}}\right)$ were measured by thermodilution method. Hemodynamic indices were digitized in real time at a sampling rate of $200 \mathrm{~Hz}$ with a data acquisition system (PowerLab; AD Instruments, Inc, Mountain View, Calif) and stored on a hard disk for subsequent analysis. Changes in LV volumes were assessed before and after sizing the Coapsys device by a 3-dimensional (3-D) ultrasound system (Volumetrics Medical Imaging Inc, Durham, NC). Subsequently, LV end-diastolic (LVEDV) and endsystolic (LVESV) volumes were determined by rotated apical 6-plane views with multiplanar Simpson method. ${ }^{14}$ Stroke work $($ stroke work $=[$ LVEDV - LVESV $] \times[$ LV end-systolic pressure - LV end-diastolic pressure] $\times 0.0136)$ and ejection fraction $($ ejection fraction $=[$ LVEDV - LVESV $] /$ LVEDV $\times 100)$ were 

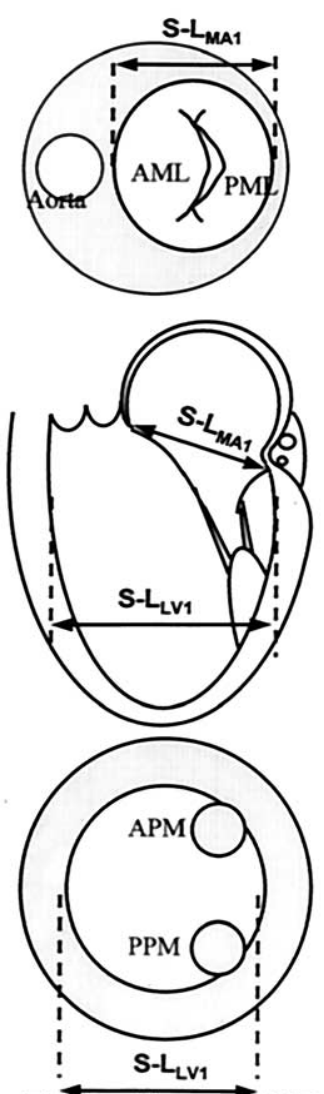

Functional MR

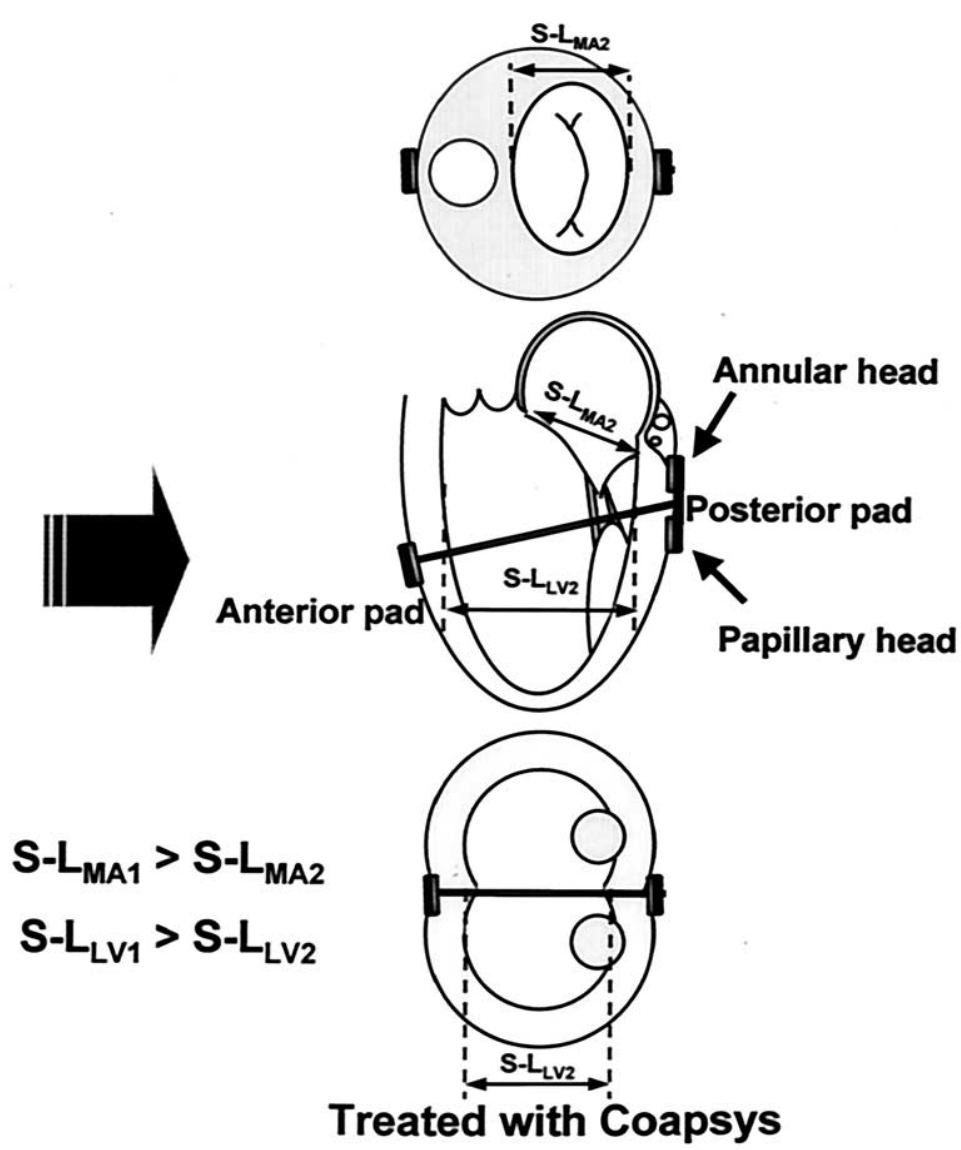

Figure 2. The annular head of the posterior pad was located at the mitral annular level and worked to reduce the septal-lateral dimension of the mitral annulus. The papillary head of the posterior pad was located at the midpapillary level to change the papillary muscle position toward the left ventricular septum. $A M L$, Anterior mitral leaflet; $P M L$, posterior mitral leaflet; $S$ - $L_{M A 1}$, mitral annular septal-lateral dimension 1; $S$ - $L_{M A 2}$, mitral annular septal-lateral dimension 2; $S-L_{L V 1}$, left ventricular septal-lateral dimension 1; $S$ - $L_{L V 2}$ left ventricular septal-lateral dimension 2.

calculated. Transthoracic 2-D images were obtained to assess MR, TR, and aortic regurgitation (AR) by color Doppler imaging. The mitral annular septal-lateral $\left(\mathrm{S}-\mathrm{L}_{\mathrm{MA}}\right)$ dimension was measured using the long-axis view and the mitral annular commissurecommissure $\left(\mathrm{C}-\mathrm{C}_{\mathrm{MA}}\right)$ dimension was measured using the 2-chamber view at end-diastole and end-systole. The LV cross-sectional dimensions in septal-lateral $\left(\mathrm{S}-\mathrm{L}_{\mathrm{LV}}\right)$ and commissure-commissure $\left(\mathrm{C}-\mathrm{C}_{\mathrm{LV}}\right)$ planes were measured at midpapillary muscle level. MR volume and effective regurgitant orifice area (EROA) were calculated using the continuity equation. ${ }^{15} \mathrm{MR}$ jet area, the ratio of MR jet area to left atrial area (MR/LA ratio), annular area, and peak MV pressure gradient were also measured. A sternotomy was performed and the chest was opened. Just prior to opening the chest, a continuous infusion of lidocaine was started at $1 \mathrm{mg} / \mathrm{kg} / \mathrm{h}$ to prevent ventricular arrhythmias. A 14-mm Transonic flow probe (model no. 14A165, Transonic Systems Inc, Ithaca, NY) was placed on the ascending aorta and connected to a flow meter (Model T106, Transonic Systems Inc) to measure cardiac output $\left(\mathrm{CO}_{\mathrm{FP}}\right)$ and stroke volume $\left(\mathrm{SV}_{\mathrm{FP}}\right)$. A Millar catheter (model SPC-
350; Millar Instruments, Inc) was inserted into the LA to monitor LA pressure (LAP).

The Coapsys device was surgically implanted. The appropriate sites for the Coapsys device placement were identified through a combination of external landmarks and 2-D echocardiographic visualization of internal structures to avoid compromise of papillary muscles, mitral apparatus, or main coronary artery branches. The position of the posterior pad was approximately $2.5 \mathrm{~cm}$ from the atrioventricular groove and midway between the papillary muscles. The anterior pad was positioned at the apical edge of the base of the RV outflow tract and approximately $2 \mathrm{~cm}$ to the RV side of the left anterior descending artery. Following site identification, the delivery instrument was fixed to the heart utilizing vacuum assistance. A needle assembly, consisting of a stylet and hollow catheter, was then inserted through the delivery instrument from the anterior wall. Following passage of the needle assembly, the stylet was removed and the subvalvular chord threaded through the catheter and pulled through both walls. The subvalvular chord was drawn through the ventricle until the posterior pad rested on 
the LV wall. The anterior pad was inserted over the anterior side of the subvalvular chord. Hemodynamic and echocardiographic measurements were recorded as the presizing data point. Following Coapsys device placement, the subvalvular chord leader was then secured to the sizing instrument. The Coapsys device was then tightened by drawing the posterior leaflet and annulus toward the anterior leaflet. The deployment level was selected when MR was minimized or eliminated as assessed by color Doppler images. The device size (epicardial to epicardial measurement) was obtained as the presizing and postsizing measurements (measured as percent linear reduction from presizing measurement). The Coapsys device was fixed at the deployment level. Hemodynamic and echocardiographic measurements were repeated as the postsizing data point. The chest was then closed in the standard fashion.

Postoperative analgesics and antibiotics were administrated, but no anticoagulants or antiplatelet drugs were administrated. To avoid the natural recovery of the LV and MV performance after cessation of pacing, rapid pacing at 190 beats per minute was started 3 days after surgery and maintained for 8 weeks until the terminal study. ${ }^{12}$ Each dog was given furosemide $(40 \mathrm{mg} / \mathrm{d})$ during the postoperative period. One dog was unable to eat or drink after the implantation surgery due to severe heart failure. This dog was treated with hyperalimentary therapy and discontinued pacing for 1 week (data from this animal were included in all data points). Another dog died on postoperative day 14 due to an ascending aortic rupture, which was induced by the chronically implanted aortic flow probe (data from this animal were included in baseline closed-chest, presizing, and postsizing data points).

\section{Terminal Study}

Eight weeks after the Coapsys implantation, the animals were again anesthetized and hemodynamic monitoring lines were replaced. Hemodynamic and echocardiographic measurements were performed as terminal closed-chest data point. After obtaining all data, the chest was opened, and hemodynamic and echocardiographic measurements were performed as terminal open-chest data point. Under 2-D echocardiographic guidance, the Coapsys subvalvular chord was cut utilizing a laparoscopic scissor introduced into the LV through a purse-string suture on the apex to verify that maintenance of the valve competency was due to the device (model verification). Hemodynamic and echocardiographic measurements were again performed and recorded as subvalvular chord-cut data point.

All animals were put to death and complete autopsies were performed. The hearts were excised, and the device's relationship to the coronary vessels and intraventricular structures was examined.

\section{Statistical Analysis}

Data were expressed as mean \pm standard deviation. For the acute evaluation, there was 1 pair of data: presizing and postsizing. For the chronic evaluation, there were 3 pairs of data: closed-chest (baseline and terminal) and open-chest (presizing and terminal open-chest and postsizing and terminal open-chest). For the model verification, there were 2 pairs of data: terminal open-chest and subvalvular chord-cut, and presizing and subvalvular chord-cut. A paired $t$ test was used for each paired data.

\section{Results}

All Coapsys device implantations were performed on beating hearts without the aid of CPB. The hemodynamic data during the implantation procedure were stable in all cases. The mean device sizes at presizing and postsizing were 6.9 $\pm 0.6 \mathrm{~cm}$ and $5.0 \pm 0.2 \mathrm{~cm}$, respectively. The mean percent linear reduction from presizing measurement was $26.4 \% \pm$ $6.9 \%$.

Table 1 summarizes the echocardiographic findings. By 2-D echocardiography, MR was reduced in all animals. MR decreased from $2.9 \pm 0.7$ at presizing to $0.7 \pm 0.8$ at postsizing $(P=.00005)$ and from $2.5 \pm 0.8$ at baseline closed-chest to $0.8 \pm 0.8$ at terminal closed-chest $(P=$ .002). MR increased from $0.8 \pm 0.8$ at terminal closed-chest to $1.9 \pm 0.7$ at terminal open-chest $(P=.041)$. MR returned to $3.6 \pm 0.8$ after cutting the Coapsys subvalvular chord $(P$ $=.001 \mathrm{vs}$ terminal open-chest). There was no significant difference in MR grade between presizing and subvalvular chord-cut (Figure 3). End-diastolic and end-systolic S-L $\mathrm{L}_{\mathrm{MA}}$ dimensions decreased significantly at postsizing and terminal closed-chest and increased significantly after cutting the subvalvular chord (Figure 4 ). The $\mathrm{C}-\mathrm{C}_{\mathrm{MA}}$ dimensions were unchanged (Figure 5). End-diastolic and end-systolic $\mathrm{S}-\mathrm{L}_{\mathrm{LV}}$ dimensions also decreased significantly at postsizing and terminal closed-chest and increased significantly after cutting the subvalvular chord. The end-diastolic C-C $\mathrm{C}_{\mathrm{LV}}$ dimension at postsizing increased significantly and end-systolic $\mathrm{C}-\mathrm{C}_{\mathrm{LV}}$ dimension decreased significantly after cutting the subvalvular chord. There were no significant differences in $\mathrm{S}-\mathrm{L}_{\mathrm{LV}}$ and $\mathrm{C}-\mathrm{C}_{\mathrm{LV}}$ dimensions between presizing and terminal subvalvular chord-cut. At terminal open-chest, both S- $\mathrm{L}_{\mathrm{MA}}$ and $\mathrm{S}-\mathrm{L}_{\mathrm{LV}}$ dimensions decreased significantly compared with those at presizing and increased significantly compared with those at postsizing. There were significant decreases in EROA and MR volume between presizing and postsizing and baseline closed-chest and terminal closedchest. EROA and MR volume increased from terminal closed-chest to terminal open-chest $(P=.048$ and $P=.028$, respectively) and from terminal open-chest to subvalvular chord-cut $(P=.023$ and $P=.054$, respectively). MR jet area and MR/LA area ratio improved after the Coapsys implantation and was maintained for 8 weeks. Annular area decreased from $4.7 \pm 0.6 \mathrm{~cm}^{2}$ at presizing to $3.3 \pm 0.5 \mathrm{~cm}^{2}$ at postsizing; $P=.0003$ ). Peak MV pressure gradient was unchanged and revealed no mitral stenosis. There were no significant changes in TR and AR.

By 3-D echocardiographic calculation, LVEDV (70 \pm $28 \mathrm{~mL}$ to $46 \pm 19 \mathrm{~mL} ; P=.013)$ and $\operatorname{LVESV}(54 \pm 23 \mathrm{~mL}$ to $30 \pm 20 \mathrm{~mL} ; P=.016)$ decreased significantly at postsizing. There was no significant change in LVEDV or LVESV between baseline closed-chest and terminal closedchest. LVEDV and LVESV significantly decreased from 
TABLE 1. 2-D and 3-D echo findings

\begin{tabular}{|c|c|c|c|c|c|c|}
\hline & \multirow{2}{*}{$\begin{array}{c}\text { Baseline } \\
\text { closed- } \\
\text { chest } \\
(n=7)\end{array}$} & \multicolumn{2}{|c|}{ Implantation } & \multicolumn{3}{|c|}{ Terminal } \\
\hline & & $\begin{array}{l}\text { Presizing } \\
(\mathrm{n}=7)\end{array}$ & $\begin{array}{l}\text { Postsizing } \\
(\mathrm{n}=7)\end{array}$ & $\begin{array}{l}\text { Closed- } \\
\text { chest } \\
(n=6)\end{array}$ & $\begin{array}{l}\text { Open- } \\
\text { chest } \\
(n=6)\end{array}$ & $\begin{array}{c}\text { Subvalvular } \\
\text { chord-cut } \\
(n=6)\end{array}$ \\
\hline \multicolumn{7}{|l|}{ 2-D echo findings } \\
\hline MR (grade) & $2.5 \pm 0.8$ & $2.9 \pm 0.7$ & $0.7 \pm 0.8^{*}$ & $0.8 \pm 0.8 \dagger$ & $1.9 \pm 0.7 \ddagger^{\prime} \S$ & $3.6 \pm 0.8 \|$ \\
\hline TR (grade) & $2.4 \pm 0.9$ & $2.6 \pm 1.4$ & $2.4 \pm 1.3$ & $2.3 \pm 0.4$ & $2.6 \pm 0.5$ & $2.9 \pm 0.7$ \\
\hline AR (grade) & $0.7 \pm 0.8$ & $1.0 \pm 0.6$ & $1.0 \pm 0.6$ & $0.7 \pm 0.8$ & $1.0 \pm 0.7$ & $0.8 \pm 0.8$ \\
\hline $\mathrm{EROA}\left(\mathrm{mm}^{2}\right)$ & $\begin{array}{l}11 \pm 2 \\
(\mathrm{n}=6)\end{array}$ & $\begin{array}{c}6 \pm 3 \\
(n=6)\end{array}$ & $\begin{array}{c}1 \pm 1^{*} \\
(n=6)\end{array}$ & $\begin{array}{l}3 \pm 0.4 \dagger \\
(n=5)\end{array}$ & $\begin{array}{c}7 \pm 4 \S \\
(n=5)\end{array}$ & $\begin{array}{l}10 \pm 2 \| \\
(n=5)\end{array}$ \\
\hline MR volume (mL/beat) & $\begin{array}{c}11.1 \pm 1.9 \\
(\mathrm{n}=6)\end{array}$ & $\begin{array}{c}7.1 \pm 3.3 \\
(n=6)\end{array}$ & $\begin{array}{c}2.6 \pm 2.2^{*} \\
(\mathrm{n}=6)\end{array}$ & $3.0 \pm 1.1 \dagger$ & $\begin{array}{c}7.3 \pm 2.9 \\
(n=5)\end{array}$ & $\begin{array}{c}10.9 \pm 3.3 \\
(n=5)\end{array}$ \\
\hline MR area $\left(\mathrm{cm}^{2}\right)$ & $3.4 \pm 2.1$ & $3.6 \pm 1.3$ & $1.0 \pm 0.4^{*}$ & $1.1 \pm 0.8 \dagger$ & $1.9 \pm 1.2$ & $5.9 \pm 2.1 \|$ \\
\hline MR/LA area ratio $(\%)$ & $26 \pm 12$ & $32 \pm 8$ & $10 \pm 4^{*}$ & $11 \pm 8 t$ & $19 \pm 13$ & $48 \pm 16 \|$ \\
\hline Annular area $\left(\mathrm{cm}^{2}\right)$ & $\begin{array}{c}4.9 \pm 0.7 \\
(n=6)\end{array}$ & $4.7 \pm 0.6$ & $3.3 \pm 0.5^{*}$ & $\begin{array}{c}4.4 \pm 0.1 \\
(\mathrm{n}=5)\end{array}$ & $\begin{array}{c}4.3 \pm 0.3 \S \\
(n=5)\end{array}$ & $5.4 \pm 0.6 \| \emptyset$ \\
\hline Peak MV gradient $(\mathrm{mm} \mathrm{Hg})$ & $1.08 \pm 0.51$ & $0.84 \pm 0.30$ & $0.82 \pm 0.46$ & $0.55 \pm 0.27$ & $0.89 \pm 0.52$ & $0.94 \pm 0.20$ \\
\hline$S-L_{M A}$ dimension, ED $(\mathrm{cm})$ & $2.3 \pm 0.3$ & $2.4 \pm 0.2$ & $1.5 \pm 0.3^{*}$ & $1.8 \pm 0.1 \dagger$ & $2.1 \pm 0.3 \S$ & $2.3 \pm 0.2 \|$ \\
\hline$S-L_{M A}$ dimension, $E S(\mathrm{~cm})$ & $2.3 \pm 0.2$ & $2.4 \pm 0.2$ & $1.6 \pm 0.2^{*}$ & $1.8 \pm 0.2 \dagger$ & $2.0 \pm 0.2 \ddagger^{\prime} \S$ & $2.4 \pm 0.2 \|$ \\
\hline $\mathrm{C}-\mathrm{C}_{\mathrm{MA}}$ dimension, ED $(\mathrm{cm})$ & $2.8 \pm 0.3$ & $2.8 \pm 0.3$ & $2.6 \pm 0.5$ & $2.7 \pm 0.3$ & $2.8 \pm 0.2$ & $2.8 \pm 0.3$ \\
\hline $\mathrm{C}-\mathrm{C}_{\mathrm{MA}}$ dimension, $\mathrm{ES}(\mathrm{cm})$ & $2.9 \pm 0.3$ & $2.8 \pm 0.2$ & $2.6 \pm 0.5$ & $2.8 \pm 0.3$ & $3.0 \pm 0.3$ & $3.0 \pm 0.3$ \\
\hline$S-L_{L V}$ dimension, ED $(\mathrm{cm})$ & $4.8 \pm 0.2$ & $4.1 \pm 0.4$ & $2.4 \pm 0.2^{*}$ & $3.3 \pm 0.4 \dagger$ & $3.3 \pm 0.5 \ddagger^{\prime} \S$ & $4.2 \pm 0.4 \|$ \\
\hline$S-L_{L V}$ dimension, $E S(\mathrm{~cm})$ & $4.5 \pm 0.3$ & $3.9 \pm 0.5$ & $2.4 \pm 0.3^{*}$ & $3.4 \pm 0.5 \dagger$ & $3.3 \pm 0.4 \ddagger^{\prime} \S$ & $4.0 \pm 0.5 \|$ \\
\hline $\mathrm{C}-\mathrm{C}_{\mathrm{LV}}$ dimension, $\mathrm{ED}(\mathrm{cm})$ & $4.7 \pm 0.6$ & $4.8 \pm 0.6$ & $5.3 \pm 0.5^{*}$ & $5.1 \pm 0.4$ & $5.3 \pm 0.5$ & $5.3 \pm 0.6$ \\
\hline $\mathrm{C}-\mathrm{C}_{\mathrm{LV}}$ dimension, $\mathrm{ES}(\mathrm{cm})$ & $4.3 \pm 0.6$ & $4.3 \pm 0.5$ & $4.6 \pm 0.5$ & $4.6 \pm 0.4$ & $4.7 \pm 0.4$ & $4.4 \pm 0.5 \|$ \\
\hline \multicolumn{7}{|l|}{$3-D$ echo findings } \\
\hline LVEDV (mL) & $82 \pm 14$ & $70 \pm 28$ & $46 \pm 19^{*}$ & $75 \pm 16$ & $58 \pm 12$ & $65 \pm 10 \|$ \\
\hline LVESV (mL) & $65 \pm 14$ & $54 \pm 23$ & $30 \pm 20^{*}$ & $59 \pm 17$ & $44 \pm 12$ & $48 \pm 12$ \\
\hline $\mathrm{SW}(\mathrm{g} \cong \mathrm{m})$ & $14.9 \pm 4.7$ & $14.3 \pm 4.7$ & $13.4 \pm 4.7$ & $16.0 \pm 4.8$ & $13.4 \pm 3.5$ & $16.4 \pm 3.6$ \\
\hline $\mathrm{EF}(\%)$ & $21.8 \pm 12.2$ & $23.8 \pm 11.0$ & $38.4 \pm 19.7$ & $21.6 \pm 7.7$ & $24.0 \pm 6.8$ & $26.7 \pm 9.6$ \\
\hline
\end{tabular}

2-D, 2-dimensional; 3-D, 3-dimensional; $M R$, mitral regurgitation; $T R$, tricuspid regurgitation; $A R$, aortic regurgitation; $E R O A$, effective regurgitant orifice area; $M R$ area, MR jet area; $M R / L A$ area ratio, ratio of MR jet to left atrial area; $S$ - $L_{M A}$, mitral annular septal-lateral; $E D$, end-diastole; $E S$, end-systole; $C$ - $C_{M A}$, mitral annular commissure-commissure; $S-L_{L V}$, left ventricular septal-lateral dimension at midpapillary muscle level; $C$ - $C_{L V}$ left ventricular dimension at commissure-commissure plane at midpapillary muscle level; MV, mitral valve; LVEDV, LV end-diastolic volume; LVESV, LV end-systolic volume; SW, LV stroke work; $E F$, ejection fraction.

Some results were not included because the requested measurements were not taken during the study or images were poor.

${ }^{*} P<.05$ vs presizing.

$\dagger P<.05$ vs baseline closed-chest.

$\ddagger P<.05$ vs presizing.

$\S P<.05$ vs postsizing.

$\| P<.05$ vs open-chest.

$\Uparrow P<.05$ vs presizing.

terminal closed chest to terminal open chest $(P=.021$ and $P=.01$, respectively). After cutting of the Coapsys subvalvular chord, LVEDV increased significantly $(58 \pm 12$ $\mathrm{mL}$ to $65 \pm 10 \mathrm{~mL} ; P=.008$ ).

Despite the significant decreases in LV volumes, there were no significant changes in $\mathrm{CO}_{\mathrm{FP}}(1.71 \pm 0.55 \mathrm{~L} / \mathrm{min}$ to $1.63 \pm 0.49 \mathrm{~L} / \mathrm{min} ; P=.144)$ or $\mathrm{SV}_{\mathrm{FP}}(19.2 \pm 8.3 \mathrm{~mL}$ to $18.4 \pm 7.7 \mathrm{~mL} ; P=.196$ ) between presizing and postsizing. There were no significant changes in $\mathrm{CO}_{\mathrm{SG}}$ and $\mathrm{SV}_{\mathrm{SG}}$ chronically. The mean AoP (77 $\pm 20 \mathrm{~mm} \mathrm{Hg}$ to $73 \pm 18$ $\mathrm{mm} \mathrm{Hg} ; P=.011)$ and systolic LVP $(91 \pm 20 \mathrm{~mm} \mathrm{Hg}$ to $86 \pm 18 \mathrm{~mm} \mathrm{Hg} ; P=.012$ ) decreased slightly but statistically significantly at postsizing. There were no significant changes in mean AoP and systolic LVP chronically. The heart rate increased at terminal closed-chest $(100 \pm 20$ beats per minute to $116 \pm 18$ beats per minute; $P=.046$ ), and the heart rate at terminal open-chest increased significantly compared with pre- and postsizing. The LAP at terminal open-chest decreased significantly compared with pre- and postsizing. In other hemodynamic parameters, there were no significant differences between presizing and postsizing and baseline closed-chest and terminal closed-chest. There were no significant differences between terminal open-chest and terminal subvalvular chord-cut and between presizing and subvalvular chord-cut in all hemodynamic parameters (Table 2). 


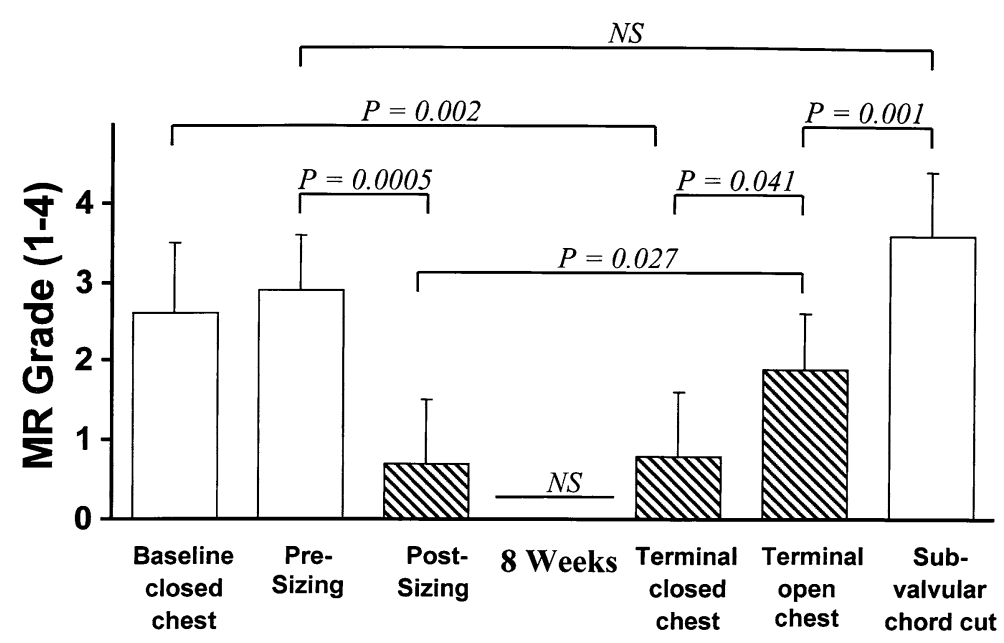

Figure 3. MR decreased significantly from $2.9 \pm 0.7$ at presizing to $0.7 \pm 0.8$ at postsizing. MR decreased significantly from $2.5 \pm 0.8$ at baseline closed-chest to $0.8 \pm 0.8$ at terminal closed-chest. When the Coapsys subvalvular chord was cut, MR increased significantly from $1.9 \pm 0.7$ to $3.6 \pm 0.8$, and there was no significant difference between presizing and subvalvular chord-cut.

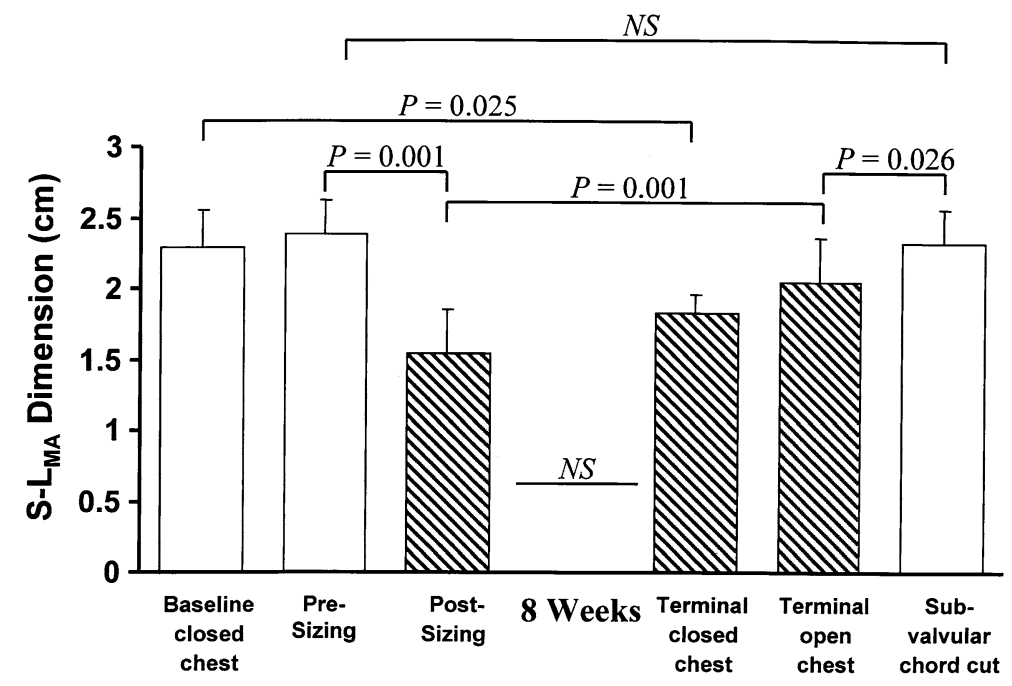

Figure 4. Mitral annular septal-lateral $\left(S-L_{M A}\right)$ dimensions in end-diastolic. The $S-L_{M A}$ dimension decreased acutely (from $2.4 \pm 0.2 \mathrm{~cm}$ at presizing to $1.5 \pm 0.3 \mathrm{~cm}$ at postsizing; $P=.001$ ). After 8 weeks follow-up, the change was maintained (from $2.3 \pm 0.3 \mathrm{~cm}$ at baseline closed-chest to $1.8 \pm 0.1 \mathrm{~cm}$ at terminal closed-chest; $P=.025$ ). There was significant increase from $1.5 \pm 0.3 \mathrm{~cm}$ at postsizing to $2.1 \pm 0.3 \mathrm{~cm}$ at terminal open-chest $(P=.001)$. After cutting the Coapsys subvalvular chord, the $S-L_{M A}$ dimension increased significantly compared with that at terminal open-chest. There was no significant change between presizing and subvalvular chord-cut.

At the time of autopsy, there were no injuries identified to the papillary muscles, MV apparatus, or main coronary artery and vein branches. The epicardial pads were firmly seated on the tissue with no evidence of erosion. Examination of downstream organs revealed no infarction or emboli. There was no thrombosis on the expanded polytetrafluoroethylene-covered subvalvular chords.

\section{Discussion}

The Coapsys device reduced functional MR acutely and chronically in the pacing-induced canine model. MR was reduced in all animals; the mean MR decreased from $2.9 \pm$ 0.7 at presizing to $0.7 \pm 0.8$ at postsizing and was maintained for 8 weeks. MR immediately reappeared after cutting the Coapsys subvalvular chord. The S-L $\mathrm{L}_{\mathrm{MA}}$ dimension 


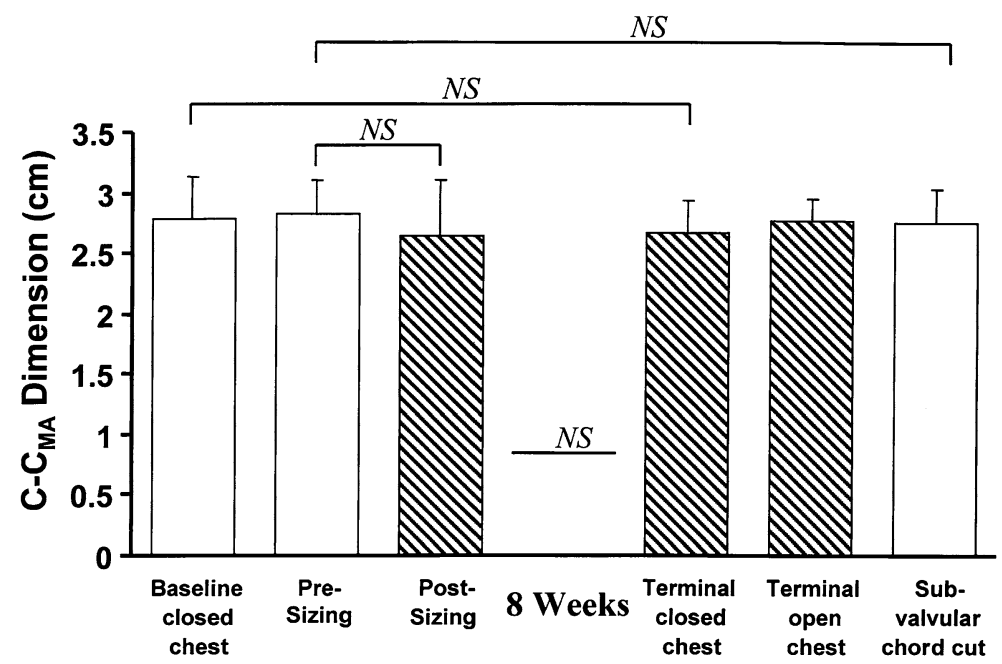

Figure 5. Mitral annular commissure-commissure $\left(C-C_{M A}\right)$ dimensions were unchanged in end-diastole.

TABLE 2. Hemodynamics

\begin{tabular}{|c|c|c|c|c|c|c|}
\hline & \multirow{2}{*}{$\begin{array}{c}\text { Baseline } \\
\text { closed-chest } \\
(\mathbf{n}=7)\end{array}$} & \multicolumn{2}{|c|}{ Implantation } & \multicolumn{3}{|c|}{ Terminal } \\
\hline & & $\begin{array}{l}\text { Presizing } \\
(\mathrm{n}=7)\end{array}$ & $\begin{array}{l}\text { Postsizing } \\
(\mathrm{n}=7)\end{array}$ & $\begin{array}{l}\text { Closed-chest } \\
(\mathrm{n}=6)\end{array}$ & $\begin{array}{l}\text { Open-chest } \\
(n=6)\end{array}$ & $\begin{array}{l}\text { Subvalvular chord-cut } \\
\qquad(\mathrm{n}=6)\end{array}$ \\
\hline HR (beats/min) & $100 \pm 20$ & $92 \pm 10$ & $92 \pm 10$ & $116 \pm 18 \dagger$ & $103 \pm 10 \ddagger \S$ & $99 \pm 10$ \\
\hline $\mathrm{CO}_{\mathrm{SG}}(\mathrm{L} / \mathrm{min})$ & $1.88 \pm 0.48$ & NA & NA & $1.91 \pm 0.35$ & NA & NA \\
\hline $\mathrm{CO}_{\mathrm{FP}}(\mathrm{L} / \mathrm{min})$ & NA & $1.71 \pm 0.55$ & $1.63 \pm 0.49$ & $N A$ & $2.34 \pm 0.72$ & $2.52 \pm 0.87$ \\
\hline $\mathrm{SV}_{\mathrm{SG}}(\mathrm{mL})$ & $19.5 \pm 6.5$ & NA & NA & $17.0 \pm 4.7$ & NA & NA \\
\hline $\mathrm{SV}_{\mathrm{FP}}(\mathrm{mL})$ & NA & $19.2 \pm 8.3$ & $18.4 \pm 7.7$ & NA & $22.7 \pm 6.7$ & $25.0 \pm 7.0$ \\
\hline $\mathrm{LAP}_{\mathrm{m}}(\mathrm{mm} \mathrm{Hg})$ & NA & $16.5 \pm 5.8$ & $15.5 \pm 4.6$ & NA & $12.5 \pm 2.6 \ddagger \S$ & $12.9 \pm 2.1$ \\
\hline $\operatorname{LVP}_{\text {sys }}(\mathrm{mm} \mathrm{Hg})$ & $88 \pm 13$ & $91 \pm 20$ & $86 \pm 18^{*}$ & $98 \pm 16$ & $88 \pm 6$ & $89 \pm 5$ \\
\hline $\mathrm{LVP}_{\mathrm{ed}}(\mathrm{mm} \mathrm{Hg})$ & $22.6 \pm 8.8$ & $18.2 \pm 6.9$ & $17.4 \pm 6.7$ & $22.1 \pm 8.0$ & $15.6 \pm 3.8$ & $16.4 \pm 3.5$ \\
\hline $\mathrm{dP} / \mathrm{dt}_{\max }(\mathrm{mm} \mathrm{Hg} / \mathrm{s})$ & $980 \pm 309$ & $910 \pm 317$ & $890 \pm 316$ & $1099 \pm 287$ & $888 \pm 84$ & $869 \pm 169$ \\
\hline $\mathrm{dP} / \mathrm{dt}_{\min }(\mathrm{mm} \mathrm{Hg} / \mathrm{s})$ & $-1042 \pm 325$ & $-986 \pm 326$ & $-975 \pm 294$ & $-1257 \pm 307$ & $-1003 \pm 154$ & $-951 \pm 151$ \\
\hline $\mathrm{AoP}_{\mathrm{m}}(\mathrm{mm} \mathrm{Hg})$ & $81 \pm 13$ & $77 \pm 20$ & $73 \pm 18^{*}$ & $88 \pm 18$ & $69 \pm 6$ & $71 \pm 5$ \\
\hline SVR (dynes $\left.\cong \mathrm{cm}^{-5}\right)$ & $3163 \pm 609$ & $3376 \pm 1238$ & $3238 \pm 1069$ & $3482 \pm 1418$ & $2345 \pm 1224$ & $2290 \pm 1277$ \\
\hline $\mathrm{PAP}_{\mathrm{m}}(\mathrm{mm} \mathrm{Hg})$ & $25.0 \pm 9.2$ & $20.9 \pm 9.6$ & $19.4 \pm 8.3$ & $22.6 \pm 8.7$ & $18.7 \pm 3.5$ & $20.1 \pm 2.7$ \\
\hline PVR (dynes $\cong \mathrm{cm}^{-5}$ ) & $327 \pm 151$ & $236 \pm 257$ & $214 \pm 241$ & $169 \pm 97$ & $248 \pm 159$ & $277 \pm 198$ \\
\hline PCWP (mm Hg) & $18.0 \pm 8.0$ & NA & NA & $19.6 \pm 10.1$ & $14.1 \pm 3.0$ & $14.9 \pm 2.2$ \\
\hline CVP $(\mathrm{mm} \mathrm{Hg})$ & $8.6 \pm 3.1$ & $9.4 \pm 2.6$ & $9.8 \pm 3.0$ & $10.1 \pm 2.5$ & $9.2 \pm 1.4$ & $9.5 \pm 1.3$ \\
\hline
\end{tabular}

$H R$, Heart rate; $\mathrm{CO}_{S G^{\prime}}$ cardiac output measured by thermodilution method; $C O_{F P}$, cardiac output measured by aortic flow probe; $S V_{S G}$, stroke volume measured by thermodilution method; $S V_{F P}$, stroke volume measured by aortic flow probe; $L A P_{m}$ mean left atrial pressure; $L V P_{s y s}$ LV systolic pressure; $L V P_{e d}$, LV end-diastolic pressure; SW, LV stroke work calculated by SV and LV pressures; $d P / d t_{\max }$ maximum positive rate of change of LV pressure; $d P / d t_{\text {min }}$ minimum negative rate of change of LV pressure; $A o P_{m}$ mean aortic pressure; $S V R$, systemic vascular resistance; $P A P_{m}$, mean pulmonary arterial pressure; $P V R$, pulmonary vascular resistance; $P C W P$, pulmonary capillary wedge pressure; $C V P$, central venous pressure.

${ }^{*} P<.05$ vs presizing.

$\dagger P<.05$ vs baseline closed-chest.

$\ddagger P<.05$ vs presizing.

$\S P<.05$ vs postsizing.

significantly decreased in both end-diastole and end-systole (Figure 4). Timek and associates ${ }^{16}$ determined that a $22 \% \pm$ $10 \%$ reduction in mitral annular septal-lateral dimension abolished acute ischemic MR, and in their procedure, the 3 -dimensional saddle shape of the annulus remained intact. The Coapsys device created a $21 \% \pm 3 \%$ reduction of
$\mathrm{S}-\mathrm{L}_{\mathrm{MA}}$ dimension at end-systole in this chronic animal study. The annular head of the posterior pad was located at the mitral annular level and worked to reduce the $\mathrm{S}-\mathrm{L}_{\mathrm{MA}}$ dimension. This effect on the MR is the same as what Timek and associates ${ }^{16}$ reported. The reduction of the $\mathrm{S}-\mathrm{L}_{\mathrm{MA}}$ dimension was maintained for 8 weeks. The $\mathrm{C}^{-} \mathrm{C}_{\mathrm{MA}}$ dimen- 
sion was unchanged at both end-diastole and end-systole. This becomes important when one considers work by other authors (such as Miller ${ }^{17}$ ), who suggest that the most important surgical goal in repairing the valve is to reduce and fix the mitral annular dimension in the S-L axis and not necessarily the $\mathrm{C}-\mathrm{C}$ axis.

On the other hand, some groups have suggested ventricular shape changes including papillary muscle repositioning should be used to reduce functional MR. ${ }^{5,18,19}$ Surgical LV remodeling was effective in reducing ischemic MR in an animal infarct model. ${ }^{5}$ Also in animals, an external device that repositioned papillary muscles reduced MR without compromising LV function in an ischemic MR model. ${ }^{18}$ Menicanti and associates ${ }^{19}$ reported that papillary muscle imbrication in patients undergoing ventricular reconstruction surgery reduced functional MR, which supports the concept of LV reconstruction surgery used to reduce MR. We believe that both annular reduction and papillary muscle repositioning will create the most ideal, chronically effective treatment for functional MR. In accordance with this belief, we employed a novel device to treat functional MR. The posterior pad of the Coapsys device has two heads: one to move the mitral annulus, the other to reposition the papillary muscles.

From terminal closed chest to terminal open chest, MR grade, EROA, MR volume, MR area, MR/LA area ratio, end-diastolic S- $\mathrm{L}_{\mathrm{MA}}$, and end-systolic $\mathrm{S}-\mathrm{L}_{\mathrm{MA}}$ increased and LVEDV and LVESV decreased. The significant decrease in volume is likely due to hemodynamic changes caused by opening the chest, freeing the heart of surrounding adhesions, and redistributing circulating volume, which in turn results in a reduction of annular change induced by the device and the commensurate increase in MR indices. Also, there is a possibility that this manipulation moved the Coapsys device. Additionally, continued pacing for 8 weeks after implantation may have led to progressive LV dysfunction and MR. We cut the Coapsys subvalvular chord to verify that maintenance of the valve competency was due to the device. After cutting the Coapsys subvalvular chord, all parameters regarding MR, which were improved by the Coapsys device, returned to baseline. The mitral annular and LV geometric changes also returned to the presizing condition. These results suggest that the Coapsys device maintained the reduction of functional MR.

The goal of the procedure was to mechanically coapt the MV leaflets by changing the MV annular dimensions and papillary muscle position. This fact was reflected in the reduced MR measured by echocardiography, the primary end point of this study. Echocardiographic reduction of MR is, of course, also the clinical standard for judging MV repair. We also secondarily sought to determine if there were hemodynamic changes associated with this MR reduction. The methodologies of this type of hemodynamic mea- surement are more difficult to analyze and some conflict exists between the results obtained by $\mathrm{CO}_{\mathrm{SG}}, \mathrm{CO}_{\mathrm{FP}}$, and those calculated by 3-D echo volumetrics. By direct LAP measurement, there was a significant reduction in LAP (from $16.5 \pm 5.8 \mathrm{~mm} \mathrm{Hg}$ at presizing to $12.5 \pm 2.6 \mathrm{~mm} \mathrm{Hg}$ at terminal open-chest, $P=.022$ ). Also, $\mathrm{CO}_{\mathrm{FP}}$ increased from $1.71 \pm 0.55 \mathrm{~L} / \mathrm{min}$ at presizing to $2.34 \pm 0.72 \mathrm{~L} / \mathrm{min}$ at terminal open-chest but did not reach significance. Whether these are accurate observations, or even important, are different questions. Not all patients with cardiomyopathy undergoing MV repair have an immediate improvement in hemodynamic parameters. Heart failure is more complex than just measurements of forward cardiac output. Also, unlike the Myosplint (a completely different device and concept), ${ }^{20,21}$ we were treating MR and so we did not try to obtain major changes in ventricular size or dimensions. There were, however, significant reductions in acute LV volumes. Nevertheless, as with all such animal experimental work, we need a careful randomized clinical study in a much larger population to sort through the clinical benefits of increasing MV coaptation and decreasing MR.

\section{Study Limitations}

In this animal study, we used the rapid ventricular pacinginduced functional MR model with LV dysfunction. In this model, there were usually 2 MR jets: a lateral and a medial jet. This is similar to the pattern seen in human ischemic cardiomyopathy (separated jets), whereas most patients with idiopathic dilated cardiomyopathy have a single central MR jet. ${ }^{8}$ The effect of the Coapsys device may be different in these patients. We continued rapid pacing at 190 beats per minute for 8 weeks after implantation, so somewhat mild or moderate remodeling might have occurred during that time.

There were some inconsistencies in measurements between the $\mathrm{CO}_{\mathrm{SG}}$ or $\mathrm{CO}_{\mathrm{FP}}$ and the cardiac output calculated from 3-D echo-derived LVEDV, LVESV, and 2-D echoderived MR volume. These inconsistencies are probably due to the limitation of volumetric analysis using 3-D echo. The 3-D echo data were shown to give estimates of LV volume changes with this device.

Anatomic measurements, including depth of coaptation and length of coaptation surface, would probably be a much more accurate way to judge how much to tighten the device rather than merely by interpreting color Doppler echo, and that is certainly something that will be looked at carefully in the clinical cases.

In conclusion, the Coapsys device reduced functional MR and improved parameters regarding MR acutely and chronically. In addition, we did not observe any negative impact on hemodynamic function in this animal model. The Coapsys device may be a promising new therapy for functional MR, and clinical trials are under way. 


\section{References}

1. Koelling TM, Aaronson KD, Cody RJ, Bach DS, Armstrong WF Prognostic significance of mitral regurgitation and tricuspid regurgitation in patients with left ventricular systolic dysfunction. Am Heart $J$. 2002;144:524-9.

2. Cohn JN, Ferrari R, Sharpe N, on behalf of an International Forum on Cardiac Remodeling. Cardiac remodeling - concepts and clinical implications: a consensus paper from an international forum on cardiac remodeling. J Am Coll Cardiol. 2000;35:569-82.

3. Otsuji Y, Handschumacher MD, Liel-Cohen N, Tanabe H, Jiang L, Schwammenthal E, et al. Mechanism of ischemic mitral regurgitation with segmental left ventricular dysfunction: three-dimensional echocardiographic studies in models of acute and chronic progressive regurgitation. J Am Coll Cardiol. 2001;37:641-8.

4. Timek TA, Dagum P, Lai DT, Liang D, Daughters GT, Ingels NB Jr, et al. Pathogenesis of mitral regurgitation in tachycardia-induced cardiomyopathy. Circulation. 2001;104:I47-53.

5. Liel-Cohen N, Guerrero JL, Otsuji Y, Handschumacher MD, Rudski LG, Hunziker PR, et al. Design of new surgical approach for ventricular remodeling to relieve ischemic mitral regurgitation: insights from 3-dimensional echocardiography. Circulation. 2000;101:2756-63.

6. Otuji Y, Handschumacher MD, Schwammenthal E, Jiang L, Song JK, Guerrero JL, et al. Insights from three-dimensional echocardiography into the mechanism of functional mitral regurgitation: direct in vivo demonstration of altered leaflet tethering geometry. Circulation. 1997; 96:1999-2008

7. Komeda M, Glasson JR, Bolger AF, Daughters GT II, MacIsaac A, Oesterle SN, et al. Geometric determinants of ischemic mitral regurgitation. Circulation. 1997;96:II128-33.

8. Kwan J, Shiota T, Agler DA, Popović ZB, Qin JX, Gillinov MA, et al. Geometric differences of the mitral apparatus between ischemic and dilated cardiomyopathy with significant mitral regurgitation: real-time three-dimensional echocardiography study. Circulation. 2003;107: 1135-40.

9. Fukamachi K, Inoue M, Popović ZB, Doi K, Schenk S, Nemeh H, et al. Off-pump mitral valve repair using the Coapsys device: a pilot study in a pacing-induced mitral regurgitation model. Ann Thorac Surg. 2004;77:688-92.

10. Carpentier AF, Lessana A, Relland JYM, Belli E, Mihaileanu S, Berrebi AJ, et al. The "Physio-Ring:" advanced concept in mitral valve annuloplasty. Ann Thorac Surg. 1995;60:1177-86.

11. Takagaki M, McCarthy PM, Goormastic M, Ochiai Y, Doi K, Kopcak MW Jr, et al. Determinants of the development of mitral regurgitation in pacing-induced heart failure. Circ J. 2003;67:78-82.

12. Takagaki M, McCarthy PM, Tabata T, Dessoffy R, Cardon LA, Connor J, et al. Induction and maintenance of an experimental model of severe cardiomyopathy with a novel protocol of rapid ventricular pacing. J Thorac Cardiovasc Surg. 2002;123:544-9.

13. Howard RJ, Moe GW, Armstrong PW. Sequential echocardiographicDoppler assessment of left ventricular remodeling and mitral regurgitation during evolving experimental heart failure. Cardiovasc Res. 1991;25:468-74.

14. Qin JX, Jones M, Shiota T, Greenberg NL, Tsujino H, Firstenberg MS, et al. Validation of real-time three-dimensional echocardiography for quantifying left ventricular volumes in the presence of a left ventricular aneurysm: in vitro and in vivo studies. $J$ Am Coll Cardiol. 2000;36:900-7.

15. Enriquez-Sarano M, Seward JB, Bailey KR, Tajik AJ. Effective regurgitant orifice area: a noninvasive Doppler development of an old hemodynamic concept. J Am Coll Cardiol. 1994;23:443-51.

16. Timek TA, Lai DT, Tibayan F, Liang D, Daughters GT, Dagum P, et al. Septal-lateral annular cinching abolishes acute ischemic mitral regurgitation. J Thorac Cardiovasc Surg. 2002;123:881-8.

17. Miller DC. Ischemic mitral regurgitation redux - to repair or to replace? J Thorac Cardiovasc Surg. 2001;122:1059-62.

18. Hung J, Guerrero JL, Handschumacher MD, Supple G, Sullivan S, Levine RA. Reverse ventricular remodeling reduces ischemic mitral regurgitation: echo-guided device application in the beating heart. Circulation. 2002;106:2594-600.

19. Menicanti L, Di Donato M, Frigiola A, Buckberg G, Santambrogio C,
Ranucci M, et al. Ischemic mitral regurgitation: intraventricular papillary muscle imbrication without mitral ring during left ventricular restoration. J Thorac Cardiovasc Surg. 2002;123:1041-50.

20. McCarthy PM, Takagaki M, Ochiai Y, Young JB, Tabata T, Shiota T, et al. Device-based change in left ventricular shape: a new concept for the treatment of dilated cardiomyopathy. J Thoracic Cardiovasc Surg. 2001;122:482-90.

21. Takagaki M, McCarthy PM, Ochiai Y, Dessoffy R, Doi K, Vidlund R, et al. Novel device to change left ventricular shape for heart failure treatment: device design and implantation procedure. ASAIO J. 2001; 47:244-8.

\section{Discussion}

Dr Farzan Filsoufi (New York, NY). Fifty-two years ago, the pioneering cardiac surgeon, Charles Bailey, published a paper on the surgical treatment of mitral insufficiency on a beating heart using a strip of pericardium passed through the ventricle in a fashion similar to that of this novel device. This places this interesting study in historical context.

To understand the potential applicability of this device to patients with mitral regurgitation secondary to ischemic heart disease or dilated cardiomyopathy, it is important to emphasize the pathophysiology of this condition. These patients have restricted leaflet motion during systole resulting from ventricular dilatation and papillary muscle displacement. This corresponds to type IIIb dysfunction in Carpentier's functional classification of MR. Most patients also have some degree of secondary annular dilatation, primarily in the septolateral dimension. This annular dilatation is an important factor in the pathogenesis and progression of type IIIb mitral regurgitation.

We believe the current standard of care for this condition is a downsized remodeling annuloplasty, which reshapes the annulus and increases the surface of coaptation by decreasing the septolateral dimension. Because it only treats the annular component and not the ventricular component of the dysfunction, the remodeling annuloplasty technique is associated with a small incidence of residual or recurrent mitral regurgitation.

The Coapsys device is unique in that it attempts to address both the annular and ventricular components of type IIIb MR. This is a well-designed and well-executed study in a difficult animal model with interesting results.

I have the following questions for you. My first question relates to durability. Although you demonstrate a significant reduction in MR, this decrease did not correlate with expected anatomic findings. For example, on 2-D echocardiography, the mitral valve area and the septolateral dimension actually increased by $33 \%$ and $20 \%$ over the 2-month study period. This inconsistency between the physiologic correction of the MR and the anatomic findings should be addressed. Are you concerned about this early increase in valve area and septolateral dimension and its potential impact on the long-term durability of the procedure?

My next question relates to your technique of intraoperative sizing. You rely on intraoperative echo to size the device. However, our group and others have clearly documented the downgrading of type IIIb MR by intraoperative echocardiography as a result of downloading effects of general anesthesia. Do you feel that anatomic measurements such as septolateral dimension and coaptation depth and length would be more appropriate parameters for sizing in the clinical setting? 
My third question relates to the clinical indications for the device. There is a broad spectrum of patients with type IIIb MR with regard to the severity of mitral regurgitation and the degree of left ventricular dilatation. Which patients within this spectrum do you feel are likely to have a successful, durable outcome with this device? Specifically, do you believe that it will work as sole therapy for patients with severe MR and dilated ventricles or do you see it as an adjunct to annuloplasty in these patients?

Dr McCarthy. First, we assess carefully all of the changes that we see regarding durability. One explanation for some of the differences in measurements - which, by the way, were only about $3 \mathrm{~mm}$ - is that some of those measurements were made in the acute setting with the chest open, versus later measurements with the chest closed. So there are certainly differences in loading conditions. Also, measurements are influenced by the difference in echo techniques in that the measurement of the annular area was by short axis, the measurement of the septolateral by long axis, and the commissure-to-commissure measurement by 2-chamber views. So it is hard in 2-D echoes to really recreate the total annular area and correlate it to the other 2 measurements because of the differ- ent views. Furthermore, this is a pacing model of heart failure that we had developed a few years ago, and there is ongoing pacing at a rate of 190 beats per minute. So we expect that there would be some continued remodeling during that time, which may account for some of the small changes. Nevertheless, durability is the most important issue for the clinical trials.

In terms of the technique, I completely agree that anatomic measurements, including coaptation depth and length, would probably be a much more accurate way to judge how to place the device than merely by interpreting color Doppler echo. This is certainly something that will be looked at carefully in the clinical cases.

In terms of the clinical indications, I don't know yet exactly what role this is going to have. Coapsys just recently began a randomized clinical trial in the United States with groups of patients undergoing coronary artery bypass grafting (CABG) with ring annuloplasty, patients undergoing $\mathrm{CABG}$ alone, and $\mathrm{CABG}$ with the Coapsys device. So we will be looking at how this holds up in patients with ischemic cardiomyopathy and then we can determine the proper role for Coapsys.

\section{Authoritative}

The Journal of Thoracic and Cardiovascular Surgery is the most frequently cited thoracic/cardiovascular surgery journal in the Science Citation Index. An article in JTCVS is cited on average almost twice as often as those in the closest cardiothoracic journal. 